\title{
Thermo Shrink Films with Interval Macrostructure for Protection of Packaging from Falsification
}

\author{
A. P. Kondratov ${ }^{1}$ \\ ${ }^{1}$ Moscow State University of Printing Arts named after Ivan Fyodorov, 2 A Pryanishnikov st., Moscow 127550, \\ Russia
}

Correspondence: A. P. Kondratov, Moscow State University of Printing Arts named after Ivan Fyodorov, 2 A Pryanishnikov st., Moscow 127550, Russia. E-mail: apk@newmail.ru

Received: September 18, 2014

Accepted: September 28, $2014 \quad$ Online Published: October 23, 2014

doi:10.5539/mas.v8n6p204

URL: http://dx.doi.org/10.5539/mas.v8n6p204

\begin{abstract}
A verification algorithm and new polymers to produce the elements of the counterfeit packaging protection have been suggested. Protective elements are made of polymer materials with the "shape memory" containing the parts that are significantly different in the degree and temperature of shrinkage under heating up to $95-100{ }^{\circ} \mathrm{C}$. These materials are used to print a linear bar code with the EAN-13 symbology, specially distorted in proportion to the degree of the local film shrinkage. The identity verification of the packaging is carried out by reading the bar code before and after heat treatment. The dependence of the local shrinkage degree of the internal polyvinylchloride film with the "shape memory" on the temperature of the modification of the intervals, mode and method of heat treatment applied in the verification of the package identity has been studied.
\end{abstract}

Keywords: Polyvinylchloride film, shrinkage, interval modification, packaging, falsification protection, bar code with the linear symbology, heat treatment

\section{Introduction}

At present, falsification of commodity goods of mass consumption is an urgent problem all over the world, especially in the developed countries. For these goods the method of falsification is often based on the substitution of the genuine product for the counterfeit one, with resemblance of the package and the label of the genuine product being preserved. The material and graphic printing of the package are made to look identical with the real ones (Deisler, 2000). This is the way counterfeiters try to deceive the consumer. Trying to prevent the product from being falsified, the manufacturers use unique technologies (Žiljak et al., 2009) and materials (Ostromoukhov and Hersch, 1999), embedding variable watermark information in screens (Shen-ge Wang et al, 2008). It increases the product value considerably, decreases its competitiveness but, nevertheless, counterfeiters soon master these techniques too. It results in constant demand for cheap methods of products protection from falsification by using the package that is difficult to counterfeit.

One of possible trends in the development of the techniques for packaging protection from falsification is the combination of certain material, protective coded image printed on the film and a special method of identification (Wu, 2000, Yeung, 1997). The combination of these three components is used in the protection method suggested (Kondratov and Babljuk, 2011; Kondratov et al., 2011) which is based on the polymer material. To produce such a material, it is recommended to use a polymer film as a base that is manufactured on large scale, which is relatively cheap (Kaminska, and Hasegawa, 1987; Tsitsilianis, et al., 1989).

To achieve the aim, one can use a shrinkable film (Grossman, Richard F. (Hrsg.)., 2008) that is subjected to prior thermo-mechanical modification. After treatment the modified areas of the film should lose the shrinkage capability completely or become shrinkable only at significantly higher temperatures than the initial material. Such a material is called the material with the "shape memory". In this case the zones with the "shape memory" are fixed in certain intervals, and the modified film can also be referred to as "interval". The linear size of modified intervals of a film, as a rule, is $2 \div 20 \mathrm{~mm}$. According the international scale of EAN-13 it should be $0,2 \div 0,8$ of the bar code's length

The interval film prepared is used to produce packaging onto which a bar code is printed so that a part of the code falls on the locally modified surface and the other part of the code - on the non-modified part, the bar code 
having a magnified scale in the zones which in printing fall onto the non-modified parts of the film. The magnification of the code scale is made at the stage of prior-to-printing preparation of the image proportionally with the predicted shrinkage of the non-modified intervals (Kondratov, 2011). The bar code is not accessible to reading during the primary identification of the packaging product. Then the film is exposed to general heating under which the locally modified intervals of the film do not change their dimensions, with the non-modified ones shrinking in one direction by the degree of the linear shrinkage of the initial material.

The shrinkage of the film and scaling of the barcode should be in agreement in such a way that after heating the bar code would become accessible to reading. Simultaneously it is recommended that an analogous common bat code be printed on the package, which will contain the necessary information on the properties of the product, e.g. about its price. Thus, the bar code with a partially changed scale will serve to control the authenticity of goods.

The scheme of protective marking and control of the identity of the graphic printing is presented in Fig.1.
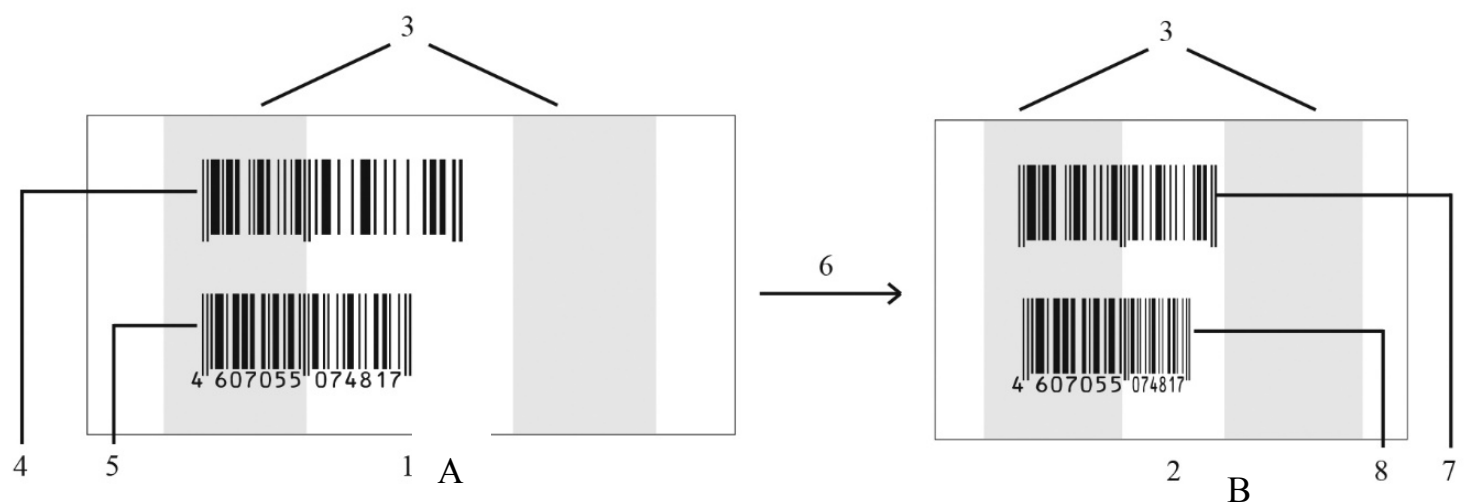

Figure 1. The scheme of the protective marking and control of the identity of the package or label, produced on an interval shrinkable film: A - a fragment of the film with the bar codes before heating; B - the same fragment after heating, 1- modified parts of the film (without shrinkage) 2-20 mm, 2- a modified code inaccessible to reading, 3 - a common bar code, 4 - heating procedure, 5 - a modified bar code accessible to reading after heating, 6 - a common bar code inaccessible to reading after heating

The given project of the protective marking production requires carrying out investigations aimed at the choice of the conditions to implement the technology of the interval modification of a specific polymer film from those that are most demanded on the packaging industry and the conditions of its heat treatment after printing protective marking to verify the identity.

\section{Technique of Researches}

Studying the physical-chemical nature of the "shape memory" effect.

To investigate the physical-chemical nature of the "shape memory" effect and to determine the optimal quantitative parameters of the modification process, a calorimetry examination of the print substrate polyvinylchloride films from different manufacturers, exposed to thermal mechanical modification, has been carried out. Polyvinylchloride films from different manufacturers have the same basic ingredients of the composition, including: polyvinyl chloride suspension (92\%), dioctyl phthalate (4\%), calcium stearate, polifenilmetilsiloksan - 4, an epoxidized soybean oil.

To carry out the calorimetric examination of the print substrates with the "shape memory", packs of micro disks with diameter of $2.0 \mathrm{~mm}$, cut out from the modified parts of the interval film samples were prepared to be put inside the crucible of the differential scanning calorimeter (DSC). Aluminum crucibles with the diameter of 5 $\mathrm{mm}$ with holes and the calorimeter with the programmed diagram processing on the PC-DSC 204 processor of the Phoenix company NETZSCH (Germany) were made use of.

Standard DSC diagrams as "sensor signal -temperature" plots were obtained from the samples of $0.5-0.7 \mathrm{~g}$ with the heating rate of the crucible $10^{\circ} \mathrm{C} / \mathrm{min}$.

To substantiate the optimal modes of the thermal-mechanical modification of the packaging materials and to study the "shape memory" effect in the interval films, the local shrinkage of the modified parts of the films was measured. 
For justification of optimum modes thermo-mechanical modifications of packing materials and studying of effect of "shape memory" in interval films carried out measurement of local shrinkage of the modified sites of films.

For receiving and research of laboratory models of protective packing from interval materials with "shape memory" the rigid thermo-shrinkable film from polyvinylchloride of the European and Russian productions was used. Narrow zones with the minimum shrinkage were created by local heat treatment at $70-112{ }^{\circ} \mathrm{C}$ samples of a film under pressure of 70 psi. Constant pressure in size was created by a short-term impact of the hot steel whetstones which temperature was maintained to within $0,5{ }^{\circ} \mathrm{C}$. Temperatures of heating are specified in the table. Received by local thermo-mechanical modification at $90-112{ }^{\circ} \mathrm{C}$ samples of interval polyvinylchloride film materials show effect of "shape memory" only in not modified intervals at the general heating of films (models of packing) from $60{ }^{\circ} \mathrm{C}$ to $100{ }^{\circ} \mathrm{C}$ both in water, and in a laminator. Radiation heating of interval materials with "shape memory" in package (office) laminator was used for modeling of process of shrinkage of the marked elements of packing in practice.

Before heating for the purpose of identification of results of shrinkage the millimetric coordinate grid was put on laboratory samples of interval films in the way of a stencil process. The grid is necessary for carrying out dilatometric measurements in processes of deformation and thermal shrinkage of films, and also for determination of width of a transitional zone.

\section{Results}

The charts received by a method of a differential scanning calorimetry in the course of first and repeated heatings of samples of thermo-shrinkable polymeric materials qualitatively differ (fig. 2). On the chart of the first heating of industrial samples of polyvinylchloride thermo-shrinkable films of production of the Don-Polymer firm, subjected short-term $(5 \mathrm{c})$ to heating with fixed sizes in boiling water, there are two exothermic peaks, apparently, to two stages of an orientation extract of a thermo-shrinkable film in the course of receiving by blower in hot water at $50 \div 60^{\circ} \mathrm{C}$ and when cooling in a tension on air $\left(20 \div 25^{\circ} \mathrm{C}\right)$ in contact with a steel surface. It will well be coordinated with experimental data of article (Bigg. 1990) confirming existence of two stages of shrinkage of such films from PVC. At repeated heating of all samples in the same crucible of a calorimeter of thermal effect it isn't observed. Charts of repeated heating are used for more correct quantitative measurement and calculation of sizes of thermal effects. If the film is subjected to modifying heat treatment under pressure of $500 \mathrm{kPa}$ within 6 seconds, the exothermic peak corresponding to "cold" shrinkage at a temperature of $20 \div 25^{\circ} \mathrm{C}$ decreases by 6 times, and the thermal effect from film shrinkage at $50 \div 60^{\circ} \mathrm{C}$ is localized in the field of temperature $-52 \div 52{ }^{\circ} \mathrm{C}$ to which the film actually heats up for a short time modifying heat treatment. The quantity of the energy which was allocated at shrinkage makes $4,1 \div 4,7$ of $\mathrm{J} / \mathrm{g}$ and practically doesn't change in the course of modification of thermo-shrinkable polyvinylchloride by local heat treatment under pressure, as. normal pressure due to friction between contacting surfaces interferes with film shrinkage during heat treatment. In places of local heat treatment under pressure former level of internal tension remains and the exothermic effect is shown in the same sizes at the subsequent heating.

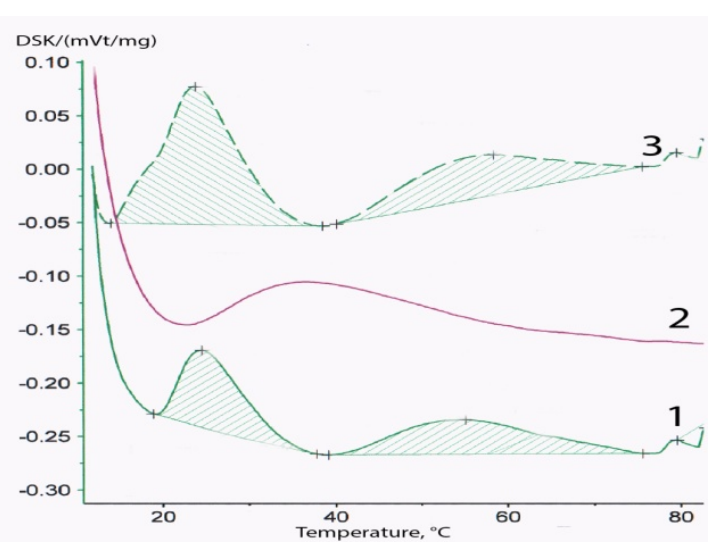

a

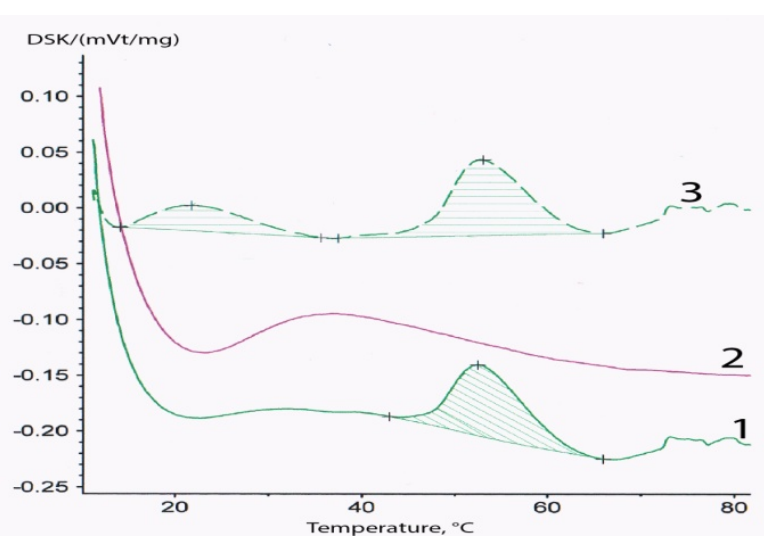

$\mathrm{b}$

Figure 2. DSK curve for samples of the focused thermoshrinkable polyvinylchloride film with characteristic exothermic peaks

a - an initial sample of a film without processing, 
b- the sample subjected to heat treatment under pressure.

1 - DSK sensor signal at the first test.

2 - DSK sensor signal at repeated heating in a calorimeter crucible.

3 - result of subtraction of curves 1 and 2.

We investigated dependence of size of shrinkage of a film in the modified zone and sites adjoining to it from modification temperature in the range of $70 \div 112{ }^{\circ} \mathrm{C}$ at time of local influence $5 \div 7$ of page. After shrinkage the distorted grid between intervals was measured in a transitional zone with microscope application. By results of measurements local shrinkage of unmodified intervals, residual size of local shrinkage of the modified sites, width of a transitional zone were defined, and also the shrinkage gradient in a transitional zone was counted. Results are given in

Table 1. Residual local shrinkage of films of polyvinylchloride of two brands 70 - 80 microns thick, determined by various techniques of total heating

\begin{tabular}{|c|c|c|c|}
\hline \multirow{2}{*}{$\begin{array}{l}\text { Brand } \\
\text { films } \\
\text { PVC }\end{array}$} & \multirow[b]{2}{*}{$\begin{array}{c}\text { Temperature of } \\
\text { heat local treatment, }{ }^{\circ} \mathrm{C}\end{array}$} & \multicolumn{2}{|c|}{ Minimum shrinkage of the interval film, $\%$} \\
\hline & & $\begin{array}{c}\text { laminator } \\
\left(100^{\circ} \mathrm{C}\right)\end{array}$ & water $\left(95-100^{\circ} \mathrm{C}\right)$ \\
\hline \multirow{4}{*}{ Shrin polyvinylchloride } & 70 & 17 & 16 \\
\hline & 75 & 17 & 10 \\
\hline & 80 & 0 & 6 \\
\hline & 85 & 0 & 11 \\
\hline \multirow[t]{5}{*}{ «Eurofilm» } & 90 & 0 & 5 \\
\hline & 92 & 0 & 0 \\
\hline & 94 & 0 & 0 \\
\hline & 96 & 0 & 0 \\
\hline & 80 & - & 0 \\
\hline \multirow[t]{2}{*}{ «Don-Polymer» } & 110 & - & 0 \\
\hline & 112 & - & 0 \\
\hline
\end{tabular}

\section{Discussion}

It is known that reduction of the sizes (shrinkage) of the focused films proceeds when heating spontaneously under the influence of internal tension (Bigg, 1990), due to the energy absorbed by polymer in the course of their linear or plane orientation. On the example of polyvinylchloride (Abdel-Naby, 2011), polystyrene and its copolymers with the metakrilovy acid, subjected to plane orientation, it was shown (Berstein and Egorov, 1990. ) that the polymeric material deformed in a vitreous state on $30 \div 40$ of $\%$, reserves to $5 \div 6$ of $\mathrm{J}$ of internal energy on polymer gram. Influence of such (forcedly-elastichesky) deformation on heatphysical constants of vitreous polymer is shown as follows. The chart DSK of the deformed polymer contains the wide exothermic peak, located lower than temperature of vitrification (fig. 2), and the chart DSK of not deformed polymer contains only endothermic peak in the field of its temperature of vitrification ( isn't shown). In process thermo-mechanical modifications the exothermic peak is gradually displaced in area of big temperatures and decreases, and then disappears completely after long heat treatment.

In many pilot studies of vitreous polymers by a method of a deformation calorimetry it is shown (15- Du and Zhang, 2010) that plastic deformation of polymeric glasses essentially differs from the corresponding process taking place in low-molecular solid bodies. The considerable part of work of deformation in an initial stage of "cold" stretching or linear compression collects a polymeric body and won't be transformed to heat (Shenogin, 2004) without additional heating of the deformed samples. For the description of features of heat- physical effects and structural and mechanical behavior of vitreous polymers some hypotheses (Courtney are offered. 1990, Abdel-Naby, and El-Hefnawy, 2003). The essence of one of these hypotheses consists in analogy between "forcedly-elastichesky deformation" and "a forcedly-elastichesky relaxation" (Oleynik. 1991). Application of conformable terms shows a community of mechanisms of deformation and the subsequent restoration of the deformed polymer at shrinkage in the course of heating to temperature of vitrification of polymer.

The conducted researches show that the physical condition of polymer in which processes of 
forcedly-elastichesky deformation and a forcedly-elastichesky relaxation are carried out is essential. The thermal effects accompanying deformation of stretching and shrinkage, have opposite signs, i.e. are exothermic or endothermic in a vitreous and vysokoela-stichesky state. In vitreous polyvinylchloride the forcedly-elastichesky relaxation proceeds with exothermic effect, and similar process in elastic amorphous and crystal polyethylene and polypropylene is accompanied by endothermic effect (Kondratov and Buldyrev, 2012).

Local shrinkage of the modified intervals is shown in various degree in dependence on temperature and a technique of its identification, i.e. from a sample of the device applied to the general heating $-\mathrm{a}$ water bath or a laminator. The received results are tabulated.

From the received results of the measurements given in table 1, it is visible that use as a technical tool of manifestation of an interval film with "shape memory" of a special cell of a laminator for fast heat treatment has almost important advantage .

Already at $80^{\circ} \mathrm{C}$ the shrinkage of the linear dimensions of the polyvinylchloride film parts earlier exposed to local heat modification is equal to zero, and the local shrinkage of the adjacent parts of the film reaches maximal values. In the transition zone of $0.6-0.8 \mathrm{~mm}$ the shrinkage gradient at the boundaries of the polyvinylchloride film parts subjected to modification is $0.48-0.89 \mathrm{~mm}$ and it depends on the type of the polymer material and the method of local modification.

Received information on the physical nature and quantitative characteristics of shrinkage of the polymeric films modified by local heat treatment, allows to choose optimum modes of creation of protective marking of packing.

\section{Conclusions}

For protection of packing against falsification application interval is offered termoshirinkable films in combination with printing on this film of the modified shaped code, with the subsequent check of authenticity of printing packing by heating in controlled conditions. Tool identification of authenticity is carried out by reading of a shaped code by scanners before thermo-shrinkage.

Optimum modes of carrying out process of modification of a termoshrinkable film on the basis of polyvinylchloride for the purpose of receiving interval sealed materials with "shape memory" and conditions of its heating after drawing a code for the purpose of determination of authenticity are investigated and chosen.

By a combination of a prepress distortion of the image of a shaped code to prepress preparation of the polymeric film consisting in creation of an interval material with a certain sizes of modified zones and a gradient of shrinkage, receive unique elements of protection of original packing of goods.

Local changing in the structure of the shrinkable polymer films under controlled conditions allows to create a new technology of protection for the brands of mass goods due to using the effect of the "shape memory" (Kondratov et al., 2011). The superiority of the suggested materials and the methods of falsification counteraction developed on their base over analogous technical solutions is the opportunity of using large-capacity polymers, high performance equipment to process thermoplastic materials into films, which requires only minor modernization. Another advantage is the application if the fast printing techniques of printing protective information on the films of the "roll to roll" type.

For increase of reliability and stability of processes of protection of packing with application of the offered methods it is expedient to continue work on a choice and a way of modification of new polymeric materials. For the purpose of reduction of time of local heat treatment up to the size less $5 \mathrm{~s}$, apparently, use of heating surfaces with a bigger thermolysis, temperature increase and pressure at the time of formation in a film of intervals with small shrinkage is required. Search and justification of ways of an intensification of marking will make a subject of further researches.

\section{Acknowledgement}

The present work is supported by the Ministry of Education and Science of Russian Federation, Contract \# 2014/87-1064 of the 30th of January 2014.

\section{References}

Abdel-Naby, A. (2011). Improvement of the Thermal, Photo and Mechanical Properties of Poly (Vinyl Chloride) in Presence of Poly (Glycidyl Methacrylate). American Journal of Applied Sciences, 8(7), 675-680.

Abdel-Naby, A., \& Hefnawy, M. E. (2003). Improvement of the thermal and mechanical properties of poly (vinyl chloride) in presence of poly (ethylene succinate). Polymer Testing, 22(1), 25-29. http://dx.doi.org/10.1016/S0142-9418(02)00044-2 
Berstein, V. A., \& Egorov, V. M. (1990). Differential scanning calorimetry in physical chemistry of polymers. Chemistry, pp. 350.

Bigg, D. M. (1990). An investigation of the shrinkage behavior of oriented PVC in a hot air tunnel. Advances in Polymer Technology, 10(2), 101-110.

Courtney, T. H. (1990). Mechanical behavior of materials. New York: McGraw-Hill.

Deisler, P. (2000). The labels against pirates, falsifying the goods of known producers. Print process, Heidelberg, English version, 4, 5-9.

Du, H., \& Zhang, J. (2010). Shape memory polymer based on chemically cross-linked poly (vinyl alcohol) containing a small number of water molecule. Colloid Polymer Science, 288, 15-24.

Grossman, R. F. (2008). Handbook of Vinyl Formulating (2nd ed.). Hoboken: John Wiley \& Sons.

Kaminska, A., \& Hasegawa, H. (1987). Effect of copolymers modifying PVC on its physical and mechanical properties and its UV-radiation resistance. Macromolek. Chem, 148, 93-102. http://dx.doi.org/ 10.1002/apmc.1987.051480109

Kondratov, A. P., \& Babljuk, E. B. (2011). Method of Protecting printing product from falsification, Patent of Russian Federation \# 2448366, IPC G06K9/00; applicant and patent holder: MSYPA, the application \#. 2010108169/08 of 04.03.2010, published 10.09.2011, Bulletin \# 26 of 20.04.2013, p 10.

Kondratov, A. P., \& Buldyrev, V. N. (2012). Polypropylene tapes with controlled optical and mechanical properties for the «SMART» packaging. Journal of International Scientific Publication: Materials, Methods \& Technologies, 6, 290-298.

Kondratov, A. P., Babljuk, E. B., Dryga, M. A., \& Anokhina, E. A. (2011). Polymer films with watermark for protected printing production. Advances in printing and media technology, IARIGAI Conference, 28, 285-291.

Oleynik, E. F. (1991). High Performance Polymers. Ed. by E. Baer, S. Moet. Berlin: Hauser Verlag, pp. 79.

Ostromoukhov, V., \& Hersch, R. D. (1999). Multi-Color and Artistic Dithering. Conference Proceedings: Computer Graphics Annual Conference Series, Los Angeles, CA, August 8-13, vol. 1. SIGGRAPH

Shen-ge Wang et al. (2008). Embedding variable watermark information in halftone screens: patent 007436977B2 US \# 11/043,480; Filed: Jan. 26, 2005; Pub. Date: Jul. 27, 2006.

Shenogin, S. V., Hohne, G. W. H., \& Salamatina, O. B., et al. (2004). High-molecular compounds, 46, 30-39.

Tsitsilianis, C., Tsapatsis, M., \& Economou, C. (1989). Effects of crystallinity on ageing phenomena in poly(vinyl chloride). Polymer, 30(10), 1861-1866.

Wu, M., Tang, E., \& Liu, B. (2000). Data Hiding in Digital Binary Image. IEEE Int. Conf. Multimedia and Expo, ICME'00, New York, USA.

Yeung, M. M., \& Mintzer, F. (1997). An Invisible Watermarking Technique for Image Verification. IEEE Int. Conf. Image Processing, 1, 680-683.

Žiljak, I., Pap, K., \& Žiljak, V. (2009). Double Separation Method for Translation of the Infrared Information into a Visible Area. Journal of Information and Organizational Sciences, 33(1), 219-225.

\section{Copyrights}

Copyright for this article is retained by the author(s), with first publication rights granted to the journal.

This is an open-access article distributed under the terms and conditions of the Creative Commons Attribution license (http://creativecommons.org/licenses/by/3.0/). 